\title{
Mechanisms of Cdc42-mediated rat MSC differentiation on micro/nano-textured topography
}

Guangwen Li ${ }^{1 a}$, Yanyan Song ${ }^{1 b}$, Mengqi Shi ${ }^{a}$, Yuanhong Du ${ }^{c}$, Wei Wang ${ }^{c}$, Yumei Zhang ${ }^{\mathrm{a}} *$.

${ }^{a}$ State Key Laboratory of Military Stomatology \& National Clinical Research Center for Oral Disease \& Shaanxi Key Laboratory of Oral Disease, Department of Prosthodontics, School of Stomatology, The Fourth Military Medical University, Xi'an 710032, China

${ }^{b}$ Department of Prosthodontics, The First Affiliated Hospital of Xinjiang Medical University, Xinjiang 830054, China

${ }^{\mathrm{c}}$ Department of Stomatology of the 463 Hospital of PLA, Shenyang 110042, China

${ }^{1}$ These author contributed equally to this work.

*Corresponding author. Tel.: +86(0)29 $13891913950 \quad$ (Y.Zhang), +86(0)24 18624067780 (W.Wang).

*Corresponding author. E-mail addresses: wqtzym@,fmmu.edu.cn (Y.Zhang), wangwei19831120@126.com (W.Wang). 


\section{[Abstract]}

Micro/nano-textured titanium surface topography promotes osteoblast differentiation and the Wnt/ $\beta$-catenin signaling pathway. However, the response of rat bone mesenchymal stem cells (MSCs) to micro/nano-textured topography, and the underlying mechanisms of its effects, are not well understood. We hypothesized that cell division cycle 42 protein (Cdc42), a key member of the Rho GTPases family, may regulate rat MSCs morphology and osteogenic differentiation by micro/nanotextured topography, and that crosstalk between $\mathrm{Cdc} 42$ and $\mathrm{Wnt} / \beta$-catenin is the underlying mechanism. To confirm the hypothesis, we first tested rat MSCs' morphology, cytoskeleton, and osteogenic differentiation on micro/nano-textured topography. We then examined the cells' Wnt pathway and Cdc42 signaling activity. The results show that micro/nano-textured topography enhances MSCs' osteogenic differentiation. In addition, the cells' morphology and cytoskeletal reorganization were dramatically different on smooth surfaces and micropitted/nanotubular topography. Ligands of the canonical Wnt pathway, as well as accumulation of $\beta$ catenin in the nucleus, were up-regulated by micro/nano-textured topography. Cdc42 protein expression was markedly increased under these conditions; conversely, Cdc42 silencing significantly depressed the enhancement of MSCs osteogenic differentiation by micro/nano-textured topography. Moreover, Cdc42si attenuated p-GSK3 $\beta$ activation and resulted in $\beta$-catenin cytoplasmic degradation on the micro/nanotextured topography. Our results indicate that $\mathrm{Cdc} 42$ is a key modulator of rat MSCs morphology and cytoskeletal reorganization, and that crosstalk between Cdc42 and Wnt $/ \beta$-catenin signaling though GSK3 $\beta$ regulates MSCs osteogenic differentiation by implant topographical cues. 


\section{Introduction}

The natural bone cell environment is comprised of a complex network of extracellular matrix molecules with nano-micro scale dimensions [1]. Micro/nanotextured biomimetic surface topography is a promising approach to create precise micro/nanocues to regulate bone cell interactions with the extracellular environment and intercellular signaling pathways. Our previous studies have shown that a micropitted/nanotubular hierarchical titanium topography promoted rat primary osteoblast [2] and MG63 cell [3-5] osteoblastic differentiation. Mesenchymal stem cells (MSCs) are thought to play a pivotal role in musculoskeletal tissue maintenance because of their intrinsic ability to self-renew and differentiate into various functional cell types [6]. MSCs differentiation can be driven by material/cell interface topography, suggesting a unique strategy to manipulate stem cells' osteoblastic lineage commitment [7-9].

But micropitted/nanotubular hierarchical topographical effects on MSCs remain to be thoroughly explored. Regarding the underlying mechanisms, recent studies demonstrated that $\mathrm{Wnt} / \beta$-catenin signaling, which is essential in bone mass and bone cell functions $[10,11]$, is activated in MSCs by rough micro-scale topography $[12,13]$. Similarly, we previously found the $\mathrm{Wnt} / \beta$-catenin pathway is involved in enhanced osteoblast differentiation on micro/nano-textured surface morphology [4]. However, it is still not understood precisely how topographical cues control such an important pathway.

The actin cytoskeleton has been shown to control activation of Wnt/ $\beta$-catenin signaling in mesenchymal cells on sand-blasted surface topography [14], and cell 
morphology remodeling and cytoskeletal organization can affect stem cell lineage commitment [15]. Furthermore, the cytoskeletal network allows cells to transfer outside mechanical stimuli into the nucleus and activates topography-induced mechanotransduction transducers on the membrane [16]. Rho GTPases, including RhoA, Rac1, and Cdc42, act as mechanotransduction receptors and play distinctive roles in regulating actin cytoskeletal reorganization.

Cell division cycle $42(\mathrm{Cdc} 42)$ protein is important in establishing cellular polarity and filipodia formation [17]. It is a node point of several complex intracellular networks and modulates multiple downstream signaling pathways. $\mathrm{Cdc} 42$ is a crucial component of $\mathrm{Wnt} / \beta$-catenin signaling in shear stress-induced osteoblasts, and GSK3 $\beta$ is its downstream target. Cdc42 inhibits the activity of GSK3 $\beta$ through phosphorylation and blocks GSK3 $\beta / \mathrm{APC} / \mathrm{Axin}$ complex formation. Inactivation of the GSK3 $\beta /$ APC/Axin complex in turn prevents $\beta$-catenin from being degraded through ubiquitination, and the protein consequently accumulates in the cytoplasm and translocates into the nucleus $[18,19]$.

Herein, we propose that the cell morphology-induced biological effects of topographical cues may be mediated by Cdc42. Specifically, we hypothesize that Cdc42 plays an important role in promoting MSCs osteogenic commitment and this phenomenon is regulated by crosstalk between $\mathrm{Cdc} 42$ and $\mathrm{Wnt} / \beta$-catenin signaling via GSK3 $\beta$. To test this hypothesis, we analyzed osteogenic differentiation, cytoskeleton organization, Cdc42 levels, and $\mathrm{Wnt} / \beta$-catenin signaling activity in rat MSCs cultured on micropitted/nanotubular surface topography. We then silenced Cdc42 expression with small interfering RNA and monitored rat MSCs osteogenic 
function as well as supposed downstream signaling events. Our results provide deeper insight into the molecular mechanisms associated with topographical cues.

\section{Methods and materials}

\subsection{Titanium surface preparation}

Discs of commercially pure titanium grade 2 sheets $\left(10 \times 10 \times 1 \mathrm{~mm}^{3}\right)$ were polished with 800,1000 , and 1500 grit silicon carbide. After ultrasonic cleaning in acetone, alcohol, and distilled water, the samples were divided into four groups ( $\mathrm{S}, \mathrm{R}$, $\mathrm{R} 5$, and R20) according to their processing methods. The S group was polished flat Ti samples. The R group referred to a micro-roughness surface fabricated by acid etched in 0.5 wt.\% hydrofluoric acid for $30 \mathrm{~min}$. R5 and R20 represented micro/nanotextured surfaces, acid-etched and further anodized in $0.5 \mathrm{wt} . \%$ hydrofluoric acid at 5 (R5) and 20 (R20) volts for $30 \mathrm{~min}$. The surface topographies were verified by fieldemission scanning electron microscopy (FE-SEM, HITACHI S-4800). The surface roughness was examined by atomic force microscopy (AFM, SPM-9600, Shimadzu Tokyo, Japan).

\subsection{Cell culture}

The rat mesenchymal stem cells (MSCs) were obtained from the bone marrow of 2-week-old Sprague-Dawley rats under the oversight of the University Research Ethics Committee of The Fourth Military Medical University. Briefly, both the femora and tibiae were dissected and the bone marrow cells flushed out by phosphate buffered saline and collected by centrifuging. Cells were plated in tissue culture flasks using $\alpha$-MEM (Gibco-life Technologies) supplemented with $10 \%$ fetal calf serum 
(Gibco-life Technologies) and kept at $37^{\circ} \mathrm{C}$ in a humidified atmosphere of $5 \% \mathrm{CO}_{2}$. The medium was changed every 3 days, and 2-4 passage cells were seeded on titanium samples in either growth medium or osteogenic medium, which was growth medium with the addition of $5 \mu \mathrm{g} / \mathrm{ml}$ ascorbic acid (Gibco-life Technologies), $7 \mathrm{mM}$ $\beta$-glycerophosphate (Sigma), and $10^{-7} \mathrm{M}$ dexamethasone (Sigma).

\subsection{Cell morphology}

Rat MSCs were placed on the samples at a density of $5 \times 10^{3}$ cells/well. After culturing for 1 day, the cells were transferred to a new 24-well plate and rinsed in PBS 3 times. The cells were fixed in $2.5 \%$ glutaraldehyde overnight and then dehydrated in $50 \%, 70 \%, 80 \%, 90 \%$, and $100 \%$ ethanol in sequence. After drying and spraying with gold, cell morphology was observed using a field emission scanning microscope.

\subsection{Actin cytoskeleton organization}

Rat MSCs were seeded on the samples at a density of $5 \times 10^{3}$ cells/well. After culturing for 3 days, the cells were transferred to a new 24-well plate and fixed with $4 \%$ paraformaldehyde in cold PBS for 20 min. The actin cytoskeleton was stained by 150 $\mu \mathrm{g} / \mathrm{ml}$ rhodamine-phalloidin (Sigma) in PBS for $40 \mathrm{~min}$ in dark, and nuclei were then stained with $0.1 \mathrm{ug} / \mathrm{ml} \mathrm{4,6-diamidino-2-phenylindole} \mathrm{(DAPI,} \mathrm{Sigma)} \mathrm{in} \mathrm{PBS} \mathrm{for} 15$ min. Cells was observed by laser confocal microscopy (Leica AF6000, Germany), and the images were captured. For semiquantitative analysis of the stress fiber formation degree, according to E. De Giglio's report [20], a five-point blind scoring system was used. Criteria scoring were the following: $1=$ scarce or no resolved F-actin stress fiber formation and predominantly cortical actin; $2=$ thin, short F-actin filament occupying 
at least $25 \%$ of the cell volume; $3=$ modest stress fiber formation of $\mathrm{F}$-actin where stress fibers are thicker and fill at least $50 \%$ of the cell volume; $4=$ wide stress fibers formation where stress fibers are thick and well-defined, many traverse the full width of the cell; $5=$ the whole cell is densely crammed with thick stress fibers, most traverse the width of the cell. At least 20 cells were counted for each substrate. Mean data \pm SD are reported.

\subsection{Gene expression}

In cells grown in osteogenic medium on four different surface topographies, quantitative real-time PCR was carried out to evaluate the expression levels of osteogenesis-related genes, including Runx-2, Osx, BMP, and BSP; canonical and noncanonical Wnt signaling-related genes including Wnt3a, Wnt1, Wnt5a, Wnt4, Wnt11, and Wnt7a; and Cdc42. Total RNA was extracted with Trizol reagent (Invitrogen-Life Technologies) according to the manufacturer's instructions. The concentration and purity of RNA were determined by optical density at wavelengths of 260 and 260:280 nm, respectively, and only samples presenting 260:280 ratios higher than 1.8 were analyzed. Complementary DNA was synthesized using $1 \mu \mathrm{g}$ of RNA through a reverse transcription reaction. Real-time PCR was carried out in a CFX96 Real-Time PCR Detection System (Bio-Rad) using SybrGreen PCR MasterMix (Applied Biosystems, CA). Relative gene expression was normalized to $\beta$-actin expression, and changes were expressed relative to the control smooth surface (S).

\subsection{Cdc42 fluorescence labeling}

To examine the expression and distribution of $\mathrm{Cdc} 42$, rat MSCs were cultured on the samples at a density of $2 \times 10^{3}$ cells/well for $72 \mathrm{~h}$. After rinsing three times with 
PBS, the cells on the samples were fixed with $4 \%$ paraformaldehyde in cold PBS for 20 min. Cell permeabilization was carried out using $0.1 \%$ Triton X-100 $500 \mu \mathrm{l} /$ well (Acros Organics, Geel, Belgium) for $15 \mathrm{~min}$ at room temperature and followed by blocking with 5\% goat serum for $1 \mathrm{~h}$. Cells were incubated overnight with a primary monoclonal antibody to Cdc42 (1:100, Cell Signal Technology, USA), and then with an FITC labeled secondary antibody (1:100, Cell Signal Technology, USA) for $1 \mathrm{~h}$ at room temperature. The actin cytoskeleton was stained by $150 \mu \mathrm{g} / \mathrm{ml}$ rhodaminephalloidin (Sigma) for $40 \mathrm{~min}$ in dark and nuclei were stained with 4,6-diamidino-2phenylindole (DAPI, Sigma) for $15 \mathrm{~min}$ in dark. The samples were mounted on a glass coverslip with an antifade kit (Prolong, Molecular Probes), and the distribution of Cdc42 in the MSCs was examined and digital images were processed by an inverted fluorescence microscope (Leica AF6000, Germany).

\subsection{Cdc42 siRNA transfection}

siRNA to Cdc42 was synthesized by RiboBio Co., Ltd. (Guangzhou, China). The siRNA sequences were named as $158,266,406$, and 513 . None of the four sequences had any similarity to any sequences of Cdc42 cDNA. Negative control siRNA (NC), which had no specific silencing effect, was also synthesized by RiboBio Co., Ltd. Transient transfection of MSCs with siRNA was performed using a Lipofectamine 2000 (Invitrogen, USA) according to the manufacturer's protocol. The Cdc42 siRNA silencing efficiency was tested by real-time PCR and Cdc42 fluorescence labeling 24 $\mathrm{h}$ after transfection. Wild type cells and negative control siRNA transfected cells were used as controls.

\subsection{Protein isolation and western blot analysis}


Wild type and Cdc42si rat MSCs were seeded on the samples at a density of $2 \times$ $10^{4}$ cells/well. After incubating for 7 days, total proteins were extracted by lysing in RIPA buffer (10 mM Tris-HCL, 1 Mm EDTA, 1\% sodium dodecyl sulfate, 1\% Nonidet P-40, 1:100 proteinase inhibitor cocktail, $50 \mathrm{mM} \beta$-glycerophosphate, and 50 $\mathrm{mM}$ sodium fluoride), and levels of Cdc42, GSK3 $\beta$, and phosphorylated GSK3 $\beta$ (pGSK3 $\beta$ ) were analyzed. Cytoplasmic and nuclear proteins were extracted with a Nuclear Extraction Kit (Milipore) to determine cytoplasmic and nuclear $\beta$-catenin expression levels. Protein concentrations were measured by a BCA protein assay kit (BioRad, USA). Aliquots of $20-30 \mu \mathrm{g}$ of each cell sample were fractionated by $10 \%$ SDS gels and electrotransferred to a polyvinylidene fluoride membrane (Milipore, USA). After blocking with 5\% bovine serum albumin (BSA, Gibco) for $1 \mathrm{~h}$, the immunoblots were incubated with primary antibodies specific to $\operatorname{Cdc} 42, \beta$-catenin, and p-GSK3 $\beta$ (Cell Signal, USA). The immunoblots were incubated with horseradish peroxidase-conjugated anti-rabbit antibody (Cell Signal Technology, USA). Immunodetection was performed using the Western-Light chemiluminescent detection system (Peiqing, China).

\subsection{Alkaline phosphatase staining}

Wild type and Cdc42si rat MSCs were seeded on the samples at a density of $2 \times$ $10^{4}$ cells/well. After incubating for 7 days in osteogenic medium, the cells were rinsed three times in PBS and lysed using lysis buffer (Promega). Lysates were stained with an alkaline phosphatase (ALP) reagent containing $p$-nitrophenyl phosphate ( $p$-NPP) as the substrate. The absorbance of $p$-NPP formed was measured at $405 \mathrm{~nm}$ by 
spectrophotometer (BioRad, USA). Cellular total protein was measured by a MicoBCA protein assay kit. ALP activity was normalized to the total protein content.

\subsection{Collagen secretion staining}

Wild type and Cdc42si rat MSCs with a concentration of $2 \times 10^{4} /$ well were cultured for 14 days in osteogenic medium and then washed with PBS three times and fixed in 4\% paraformaldehyde in cold PBS for $20 \mathrm{~min}$. Collagen was stained in a $0.1 \%$ solution of Sirius Red (Sigma, USA) in saturated picric acid for $18 \mathrm{~h}$. After washing with $0.1 \mathrm{M}$ acetic acid until the red color disappeared, images were taken. In the quantitative analysis, the stain was eluted in $500 \mathrm{ml} 0.2 \mathrm{M} \mathrm{NaOH} /$ methanol (1:1). The optical density at $540 \mathrm{~nm}$ was measured by a spectrophotometer.

\subsection{Extracellular matrix mineralization}

Rat MSCs were placed on the samples at a density of $2 \times 10^{4} /$ well and incubated for 21 days in osteogenic medium. Then the cells were rinsed in PBS and fixed with $75 \%$ ethanol for $1 \mathrm{~h}$. The cells were stained with $40 \mathrm{mM}$ Alizarin Red in distilled water ( $\mathrm{pH} 4.2$ ) for $20 \mathrm{~min}$ at room temperature, then washed gently with PBS and imaged. For the quantitative analysis, the stain was dissolved in $10 \%$ cetylpyridinum chloride in $10 \mathrm{mM}$ sodium phosphate and absorbance values were measured at $620 \mathrm{~nm}$.

\subsection{Statistical analysis}

Data were analyzed by SPSS 18.0 software. All data were presented as mean \pm standard deviation and analyzed by one-way ANOVA followed by a StudentNewman-Keuls post hoc test to identify significant differences among the groups. $p<$ 0.05 was considered statistically significant. 


\section{Results}

\subsection{Surface morphology}

Acid etching and anodic oxidation treatment successfully fabricated micropitted/nanotubular hierarchical surface topography with precisely controlled nanotube diameter. The morphology of the samples is illustrated in Fig. 1. At low magnification, the polish control group $(\mathrm{S})$ presents a relatively smooth surface with parallel tiny grooved scratches, and the micro (R) and two kinds of micro/nano surfaces (R5, R20) have an uneven distribution of relatively homogeneous micro pit morphology. Under high magnification, the $\mathrm{S}$ and $\mathrm{R}$ groups have no obvious nanoscale morphology, while the R5 and R20 groups present uniform nanotubes with average diameters of about $30 \mathrm{~nm}$ and $100 \mathrm{~nm}$, respectively. The average roughness (Ra) of S vs. R vs. R5 vs. R20 was 4.823 vs. 21.257 vs. 8.649 vs. 8.862 (nm). The surface maximum height (Rz) of $\mathrm{S}$ vs. R vs. R5 vs. R20 was 8.881 vs. 35.776 vs. 10.235 vs. 10.334 (nm) ( Fig 2).

\subsection{Micro/nano-textured topographies promote osteogenic differentiation of rat} MSCs

Rat MSCs osteogenic differentiation is up-regulated by micro/nano-textured titanium surfaces, as revealed by gene expression, ALP production, collagen secretion, and ECM mineralization (Fig. 3). The osteogenic-related gene expression quantification results in Fig. 3A demonstrate that in general, the micro/nano-textured topographies enhanced expression of Runx2, OSX, BMP, and BSP, with R20 yielding the highest enhancement. In the ALP, collagen, and ECM mineralization stain tests 
(Fig. 3B, C, and D), the denser staining color indicated increased production on the R5 and R20 surfaces relative to the smoother surfaces.

\subsection{Rat MSCs morphology is affected by micro/nano-textured topographies}

The rat MSCs displayed dramatically different shapes depending on the topography of the substrate (Fig. 8 The left WT part of picture 8). The cells on the smooth surface (S) spread well and showed round and fusiform prolongations. On the micropitted surface $(\mathrm{R})$, cells elongated markedly, and the lamellipodia and filopodia were in close contact with adjacent cells and the substrate. Relative to other surfaces, cells on the two micro/nano surfaces (R5 and R20) exhibited a smaller and more elongated spindle shape with increased nanotube diameter, and were still attached tightly to the substrates. Under high magnification, cells on the micro/nano-textured surfaces seen to extend a large number of lamellipodia and filopodia from the leading edges to sense and communicate with the surface microenvironment, a phenomenon most clearly observed on the R20 surface.

\subsection{Rat MSCs cytoskeleton organization is affected by micro/nano-textured topographies}

We cultured rat MSCs on four different topographical surfaces for 3 days and stained them with phalloidin to label the actin cytoskeleton. The actin cytoskeleton was dramatically different depending on surface topography (Fig. 9 The left WT part of picture 9). Cells on the $\mathrm{S}$ surfaces appeared flattened, with a disorderly cytoskeleton and visible actin microfilaments (score $3.0 \pm 0.7$ ). In the $\mathrm{R}$ group, the cytoskeleton spread wide and the density of actin fiber increased relative to the $\mathrm{S}$ group (score $3.5 \pm 0.5$ ). On the R5 and R20 surfaces, the cytoskeleton exhibited a polygonal, elongated and star-like morphology. The actin fibers were more bulky and 
arranged in an orderly way throughout the cytoplasm, forming a well-organized net. The stress fiber formation score of R5 and R20 was $4.4 \pm 0.8$ and 4.6 \pm 0.6 .

\subsection{Cdc42 activity is enhanced by micro/nano-textured topography}

After 7 days of culturing on the surfaces, cells' Cdc42 mRNA and protein levels were assessed by real-time PCR and western blot, respectively (Fig. 4). In general, both the Cdc42 gene expression and protein product were highest on R20, followed by R5. mRNA levels on R5 were 1.75-fold those on S, and levels on R20 were 3.75fold those on S. Immunofluorescence using a specific antibody to Cdc42 showed Cdc42 distributed diffusely in the cytoplasm. The fluorescence intensity in MSCs cultured on the R5 and R20 surfaces was stronger than that on the $\mathrm{S}$ and R surfaces (Fig. 5).

\subsection{Inhibition of Cdc42 blocks topographically-induced rat MSCs osteogenic differentiation}

To determine whether the osteogenic-promoting effect of micro/nano-textured topography is mediated specifically through Cdc42, we infected rat MSCs with Cdc42 siRNA and then assayed their osteogenic differentiation function. Generally, Cdc42 mediates enhancement of osteogenic differentiation by micro/nano-textured surface topographies (Fig.7). The Cdc42 siRNA transfection efficiency detected by real-time PCR and fluorescence staining $24 \mathrm{~h}$ after transfection showed that Cdc42 siRNA (the 266 sequence) decreased the Cdc 42 mRNA expression by about 85\% (Fig.6). Cdc42si suppressed the expression of Runx2, BMP, and BSP on the R5 and R20, but not on the S surface. OSX expression was not affected by Cdc42si. For cells grown on the $\mathrm{S}$ surface, none of the four gene levels were detectably changed by Cdc42si (Fig. 7A). Cdc42si caused a significant decrease in ALP levels, collagen secretion, and ECM 
mineralization on the R, R5, and R20, but not on the S surface (Fig. 7B, C, and D). According to the quantitative analysis, Cdc42si suppressed ALP production in MSCs on $\mathrm{R}, \mathrm{R} 5$, and $\mathrm{R} 20$ by about $20 \%, 40 \%$, and $40 \%$, respectively $(p<0.05)$. The collagen secretion depression rate was about $30 \%$ on $\mathrm{R}, 55 \%$ on $\mathrm{R} 5$, and $60 \%$ on $\mathrm{R} 20(p<0.05)$. ECM mineralization was decreased on R by about $45 \%$, and on both R5 and R20 by about $70 \%(p<0.05)$.

\subsection{The role of $\mathrm{Cdc42}$ in rat MSCs morphology and cytoskeleton reorganization}

Cdc42 siRNA transfection dramatically changed rat MSCs morphology (Fig.8) and cytoskeleton reorganization (Fig.9). SEM images show the transfected MSCs shrank, and stretched over a much smaller area. Fewer filopodia and lamellipodia were found under high magnification. Laser scanning confocal microscope images show the staining intensity of actin became attenuated and shorter.

\subsection{Wnt/ $\beta$-catenin signaling is enhanced in rat MSCs by micro/nano-textured topographies}

mRNA for Wnt ligands, as well as p-GSK3 $\beta$ and nuclear $\beta$-catenin protein levels, were assessed using real-time RT-PCR and Western blot analysis after 7 days of culturing. Generally, activity of the $\mathrm{Wnt} / \beta$-catenin signaling pathway was increased on a micro/nano-textured surface (Fig.10). The mRNA expressions of Wnt canonical pathway ligands (Wnt1 and Wnt3a) and Wnt non-canonical pathway ligand Wnt11 were significantly increased by R5 and R20 relative to the other surfaces, while the non-canonical pathway ligands Wnt5a, Wnt4, and Wnt7a were depressed by R, R5, and R20 compared to S. Densitometric analysis of the immunoblot data reveals that 
R5 and R20 enhance p-GSK3 $\beta$ expression and $\beta$-catenin nucleus accumulation compared with MSCs on the S surface. The relative protein expression of $\mathrm{p}$ GSK3 $\beta$ on $\mathrm{S}$ vs. R vs. R5 vs. R20 was 1.00 vs. 1.01 vs. 1.69 vs. 2.04 . The relative protein expression of $\beta$-catenin on $\mathrm{S}$ vs. R vs. R5 vs. R20 was 1.00 vs. 1.21 vs. 1.47 Vs. 1.92 .

\subsection{Cdc42 regulates $\beta$-catenin signaling activity}

To explore whether $\mathrm{Cdc} 42$ is upstream of $\beta$-catenin signaling and mediates it in rat MSCs in response to surface topography, we tested changes in $\beta$-catenin signaling after Cdc42 silencing (Fig.11). Cdc42si significantly attenuated enhancement of pGSK3 $\beta$ and nuclear $\beta$-catenin protein levels by R, R5, and R20. The Cdc42si inhibition effect was most potent in MSCs on the R20 surface: The p-GSK3 $\beta$ depression rate was $33 \%$ on $\mathrm{R}, 30 \%$ on $\mathrm{R} 5$, and $58 \%$ on $\mathrm{R} 20(p<0.05)$. The $\beta$-catenin depression rate was about $17 \%$ on $\mathrm{S}, 47 \%$ on $\mathrm{R}, 49 \%$ on $\mathrm{R} 5$, and $80 \%$ on $\mathrm{R} 20$ $(p<0.05)$

\section{Discussion}

Previous studies from our and other groups have demonstrated the osteogenic differentiation promoting effect of osteoblasts by micro/nano-textured implant topography. However, the roles of this surface property on MSCs lineage commitment, and the underlying mechanisms of the effect, especially the precise molecular events which regulate the Wnt/ $\beta$-catenin pathway, have not been well studied. Our present study firstly showed that a micropitted/nanotubular titanium surface topography (R5 and R20 groups) promoted MSCs osteogenic differentiation. Secondly, we found MSCs morphology and cytoskeletal dynamics were significantly 
different depending on surface topography, and this phenomenon was closely related to higher Cdc42 activity. Finally, we identified the critical role of Cdc42 in promoting osteogenic differentiation of rat MSCs and regulating crosstalk of the Wnt/ $\beta$-catenin pathway though GSK3 $\beta$. Our findings shed light on the mechanisms of topographical cues on rat MSCs commitment and may facilitate optimization of implant design.

The formation of bone is a complex process involving the commitment of MSCs to the osteoblastic cell lineage and the proliferation and differentiation of these committed precursors to mature, bone-forming osteoblasts. Due to their continued presence in adults and their lineage plasticity, MSCs are the focus of considerable research for tissue engineering and regenerative medicine applications [21]. Micro/nano-textured titanium surface topography is a promising approach to mimic natural bone micro- and nanoscale features that can stimulate initial interactions of bone cells with implants, and ultimately bone formation. Acid etching and anodic oxidation techniques have been successfully employed to generate hierarchical micro/nano-textured topographies on titanium without any apparent effect on its chemical composition [22]. Park, et al. performed extensive studies showing that TiO2 nanotubes can direct MSCs into osteogenic cells [23]. To test the MSCs responses to micro/nano-textured topography, we observed the cell morphology, cytoskeleton, gene expression, ALP production, collagen secretion and ECM mineralization. For cell morphology SEM observation, we cultured the cells on the sample for 1 day, because the cell density was $5 \times 10^{3}$ at 1 day and at day 1 we could easily observe the single cell morphology instead of cells connecting with each other. The actin cytoskeleton fluorescence staining and $\mathrm{Cdc} 42$ fluorescence staining text were performed on day 3 because the actin fiber and filopodia matured after 3 days of 
culturing. The ALP staining was performed at day 7 because ALP is an osteogenesis early differentiation index and is expressed early than collagen secretion and ECM mineralization. ECM is the latest osteogenesis differentiation index. So we performed the collagen secretion staining assay at day 14 and ECM mineralization staining assay at day 21. In line with others results, we also found that this surface topography enhanced rat MSCs osteogenic differentiation by enhancing mRNA expression of Runx2, Osx, BMP, and BSP, and increasing production of ALP, collagen, and ECM mineralization. In addition, we found rat MSCs exhibited markedly different morphology in response to smooth and micro/nano-textured surfaces. The consistent trend of enhanced rat MSCs osteogenic differentiation and distinctive cell morphology on micro/nano-textured topography suggests that this is predominantly a topography-mediated phenomenon.

Interestingly, we found that the cell shape and cytoskeleton had distinct responses to smooth vs. micropitted/nanotubular hierarchical surface topographies. On the S surface, rat MSCs displayed a flat round shape with disordered cytoskeletal arrangement, while on the R5 and R20 groups, MSCs exhibited elongated spindle morphology and extended abundant lamellipodia and filopodia projecting from the edge of the cell. It has long been known that cell morphology determines function. According to Donald Ingber's tensegrity theory [24-26], cells possess a prestressed cytoskeletal network, which allows cells to transfer outside mechanical stimuli to the cytoskeleton and then reorganize cell shape. Kilian, et al. recently reported that mesenchymal progenitors with shapes promoting increased contractility, such as starlike shapes, were more likely to commit to the osteoblastic lineage [27]. Therefore, changes in cell shape and the cytoskeleton appear to be important in stem cell commitment related to topography. Rho family small GTPases have well-established 
roles in cell shape remodeling and cytoskeleton organization, and play important roles in bone forming cells' response to mechanotransduction [28], particularly on implant surfaces with various chemistry and topographies [29].

Cdc42, a key member of the Rho family small GTPases, plays an important role in regulating cytoskeletal dynamics, cell shape, polarity, migration, cell cycle progression, cell fate determination, and numerous other cellular processes $[18,30]$. In this study, higher $\mathrm{Cdc} 42$ protein levels and denser Cdc42 immunofluorescence staining were found on the R5 and R20 surfaces, confirming the activation of Cdc42 by micro/nano-textured topography. Similarly, another recent study found Cdc42 was activated 1 day after human MSCs osteogenic induction, remained high for several days, and returned to basal level after 5 to 7 days [31]. To further determine whether the osteogenic-promoting effect of micro/nano-textured topography is mediated by Cdc42, we tested whether Cdc42si had any effects on MSCs osteogenic differentiation as mediated by surface topography. As expected, Cdc42si attenuated the micro/nano-textured surfaces' enhancement of osteogenesis gene expression except OSX, AlP production, collagen secretion, and ECM mineralization, indicating Cdc42 indeed mediates the up-regulating effects of the micro/nano-textured topography on osteogenic differentiation of MSCs. A possibility of the lack of effect on PSX expression after Cdc42si is that other signaling pathways, such as Wnt $[32,33]$ MAPK [34], and TGF- $\beta /$ Smad [35], may play a more important role in OSX expression in rat MSCs on the micro/nano-textured topographies.

Cdc42 signaling and the $\mathrm{Wnt} / \beta$-catenin pathways are highly interconnected, and both pathways are frequently activated in bone forming cells [36, 37]. Cdc42 is a key node of cellular signaling networks. Downstream regulation of $\mathrm{Cdc} 42$ signaling could 
occur through interaction and activation of more than a dozen downstream effectors, including protein kinases, lipid kinases, scaffolding proteins, and cytoskeletal interacting proteins $[17,38,39]$. Notably, activated Rho is required for Wnt3astimulated osteoblastic differentiation in C3H10T1/2 MSCs, a process mediated by stabilized $\beta$-catenin $[40,41]$. Thus, it is of particular interest to investigate whether Cdc42 interacts with components of the Wnt/ $\beta$-catenin pathway during rat MSCs osteogenic differentiation on a micro/nano-textured surface. In line with previous research, we found the micro/nano-textured surface down-regulated the ligands of the non-canonical Wnt pathway, including Wnt4, Wnt5a, and Wnt7a. In the canonical Wnt pathway, the expression of both Wnt1 and Wnt3a were up-regulated, indicating Wnt/ $\beta$-catenin signaling was activated by the micro/nano-textured topography. An important component of $\mathrm{Wnt} / \beta$-catenin is the complex comprising Axin, adenomatous polyposis coli (APC) and glycogen synthase kinase $3 \beta$ (GSK3 $\beta$ ). Phosphorylation of GSK3 $\beta$ (p-GSK3 $\beta$ ) prevents the GSK3 $\beta /$ APC/Axin complex from forming. This prevents degradation of $\beta$-catenin, so that the protein accumulates in the cytoplasm and translocates into the nucleus to regulate osteogenic gene expression [42]. As expected, in the current study, R5 and R20 increased p-GSK3 $\beta$ levels and resulted in higher nuclear $\beta$-catenin protein levels, confirming that $\mathrm{Wnt} / \beta$-catenin signaling was activated by micro/nano-textured topography.

To verify the relationship between $\mathrm{Cdc} 42$ and $\mathrm{Wnt} / \beta$-catenin signaling, we downregulated Cdc42 expression with small interfering RNA, and found the enhanced nuclear $\beta$-catenin and $\mathrm{p}$-GSK3 $\beta$ levels on micro/nano-textured topography were attenuated. This suggests that $\operatorname{Cdc} 42$ modulates $\beta$-catenin nuclear accumulation by phosphorylating GSK3 $\beta$, thus preventing $\beta$-catenin's degradation. These findings 
complement reports that $\beta$-catenin degradation increases in response to $\mathrm{Cdc} 42$ deletion because GSK3 $\beta$ inhibited [18, 41, 43]. Our results indicate Cdc42 and $\beta$ catenin crosstalk via GSK3 3 is a positive regulator of rat MSCs osteoblastic differentiation in response to topographical cues. Our study advances understanding of the mechanisms underlying cell morphology-induced MSCs osteogenic differentiation by implant surface topography. The identification of Cdc42 as an important component in the $\mathrm{Wnt} / \beta$-catenin pathway may provide an important line to other signaling networks.

Although we have identified the role of Cdc42 in MSCs morphology, osteogenic differentiation, and the $\mathrm{Wnt} / \beta$-catenin pathway, it is important to emphasize that we did not up-regulate $\mathrm{Cdc} 42$ and evaluate its effects. Others have shown that adenoviral transduction with an active mutant of Cdc42 results in robust inhibition of GSK3 $\beta$, as indicated by increased phosphorylation of GSK3 $\beta$ at the $\operatorname{Ser}^{9}$ residue $[18,44]$. These data, together with the results of our present study, indicate that Cdc42 is a critical regulator in implant topography-driven $\beta$-catenin signaling in rat MSCs.

\section{Conclusions}

In conclusion, we have shown that a micropitted/nanotubular hierarchical topography produced by etching and anodic oxidation treatment drives fusiform cell morphology and cytoskeletal reorganization as well as enhanced osteogenic differentiation in rat MSCs. We also note that crosstalk between the Cdc42 and Wnt/ $\beta$-catenin pathways though GSK3 $\beta$ modulates the osteoinductive effect of micro/nano-textured topography on rat MSCs. This finding sheds light on a novel 
mechanism involved in micro/nano-textured surface-mediated rat MSCs osteogenic differentiation and is a major step in the development of new surface modifications aiming to accelerate and enhance the process of osseointegration.

\section{Acknowledgements}

This work was supported by the National Science Foundation of China (No. 31400820 and No. 81530051) and the Program for Changjiang Scholars and Innovative Research Team in University (No. IRT13051).

\section{Reference}

[1] Oftadeh R, Perez-Viloria M, Villa-Camacho JC, Vaziri A, Nazarian A. Biomechanics and mechanobiology of trabecular bone: a review. Journal of biomechanical engineering 2015;137.

[2] Zhao L, Mei S, Chu PK, Zhang Y, Wu Z. The influence of hierarchical hybrid micro/nano-textured titanium surface with titania nanotubes on osteoblast functions. Biomaterials 2010;31:5072-82.

[3] Wang W, Liu Q, Zhang Y, Zhao L. Involvement of ILK/ERK1/2 and ILK/p38 pathways in mediating the enhanced osteoblast differentiation by micro/nanotopography. Acta biomaterialia 2014;10:3705-15.

[4] Wang W, Zhao L, Ma Q, Wang Q, Chu PK, Zhang Y. The role of the Wnt/beta-catenin pathway in the effect of implant topography on MG63 differentiation. Biomaterials 2012;33:7993-8002.

[5] Wang W, Zhao L, Wu K, Ma Q, Mei S, Chu PK, Wang Q, Zhang Y. The role of integrinlinked kinase/beta-catenin pathway in the enhanced MG63 differentiation by micro/nanotextured topography. Biomaterials 2013;34:631-40.

[6] Hwang NS, Varghese S, Elisseeff J. Controlled differentiation of stem cells. Advanced drug delivery reviews 2008;60:199-214.

[7] Dimitrievska S, Bureau MN, Antoniou J, Mwale F, Petit A, Lima RS, Marple BR. Titaniahydroxyapatite nanocomposite coatings support human mesenchymal stem cells osteogenic differentiation. Journal of biomedical materials research Part A 2011;98:576-88.

[8] Yang W, Han W, He W, Li J, Wang J, Feng H, Qian Y. Surface topography of hydroxyapatite promotes osteogenic differentiation of human bone marrow mesenchymal stem cells. Materials science \& engineering C, Materials for biological applications 2016;60:45-53. 
[9] Abagnale G, Steger M, Nguyen VH, Hersch N, Sechi A, Joussen S, Denecke B, Merkel R, Hoffmann B, Dreser A, Schnakenberg U, Gillner A, Wagner W. Surface topography enhances differentiation of mesenchymal stem cells towards osteogenic and adipogenic lineages. Biomaterials 2015;61:316-26.

[10] Liu F, Kohlmeier S, Wang CY. Wnt signaling and skeletal development. Cellular signalling 2008;20:999-1009.

[11] Tamura M, Nemoto E, Sato MM, Nakashima A, Shimauchi H. Role of the Wnt signaling pathway in bone and tooth. Frontiers in bioscience 2010;2:1405-13.

[12] Galli C, Passeri G, Ravanetti F, Elezi E, Pedrazzoni M, Macaluso GM. Rough surface topography enhances the activation of Wnt/beta-catenin signaling in mesenchymal cells. Journal of biomedical materials research Part A 2010;95:682-90.

[13] Wall I, Donos N, Carlqvist K, Jones F, Brett P. Modified titanium surfaces promote accelerated osteogenic differentiation of mesenchymal stromal cells in vitro. Bone 2009;45:17-26.

[14] Galli C, Piemontese M, Lumetti S, Ravanetti F, Macaluso GM, Passeri G. Actin cytoskeleton controls activation of Wnt/beta-catenin signaling in mesenchymal cells on implant surfaces with different topographies. Acta biomaterialia 2012;8:2963-8.

[15] Chen CS, Mrksich M, Huang S, Whitesides GM, Ingber DE. Geometric control of cell life and death. Science 1997;276:1425-8.

[16] Wang N, Butler JP, Ingber DE. Mechanotransduction across the cell surface and through the cytoskeleton. Science 1993;260:1124-7.

[17] Sinha S, Yang W. Cellular signaling for activation of Rho GTPase Cdc42. Cellular signalling 2008;20:1927-34.

[18] Hoang MV, Nagy JA, Senger DR. Cdc42-mediated inhibition of GSK-3beta improves angio-architecture and lumen formation during VEGF-driven pathological angiogenesis. Microvascular research 2011;81:34-43.

[19] Etienne-Manneville S, Hall A. Cdc42 regulates GSK-3beta and adenomatous polyposis coli to control cell polarity. Nature 2003;421:753-6.

[20] De Giglio E, Cometa S, Ricci MA, Cafagna D, Savino AM, Sabbatini L, Orciani M, Ceci E, Novello L, Tantillo GM, Mattioli-Belmonte M. Ciprofloxacin-modified electrosynthesized hydrogel coatings to prevent titanium-implant-associated infections. Acta biomaterialia 2011;7:882-91.

[21] Park J, Bauer S, Schmuki P, von der Mark K. Narrow window in nanoscale dependent activation of endothelial cell growth and differentiation on $\mathrm{TiO} 2$ nanotube surfaces. Nano letters 2009;9:3157-64.

[22] Kasten P, Beyen I, Niemeyer P, Luginbuhl R, Bohner M, Richter W. Porosity and pore size of beta-tricalcium phosphate scaffold can influence protein production and osteogenic differentiation of human mesenchymal stem cells: an in vitro and in vivo study. Acta biomaterialia 2008;4:1904-15.

[23] Park J, Bauer S, von der Mark K, Schmuki P. Nanosize and vitality: TiO2 nanotube diameter directs cell fate. Nano letters 2007;7:1686-91. 
[24] Stamenovic D, Coughlin MF. The role of prestress and architecture of the cytoskeleton and deformability of cytoskeletal filaments in mechanics of adherent cells: a quantitative analysis. Journal of theoretical biology 1999;201:63-74.

[25] Wang N, Ingber DE. Control of cytoskeletal mechanics by extracellular matrix, cell shape, and mechanical tension. Biophysical journal 1994;66:2181-9.

[26] Wang N, Tolic-Norrelykke IM, Chen J, Mijailovich SM, Butler JP, Fredberg JJ, Stamenovic D. Cell prestress. I. Stiffness and prestress are closely associated in adherent contractile cells. American journal of physiology Cell physiology 2002;282:C606-16.

[27] Kilian KA, Bugarija B, Lahn BT, Mrksich M. Geometric cues for directing the differentiation of mesenchymal stem cells. Proceedings of the National Academy of Sciences of the United States of America 2010;107:4872-7.

[28] Guignandon A, Faure C, Neutelings T, Rattner A, Mineur P, Linossier MT, Laroche N, Lambert C, Deroanne C, Nusgens B, Demets R, Colige A, Vico L. Rac1 GTPase silencing counteracts microgravity-induced effects on osteoblastic cells. FASEB journal : official publication of the Federation of American Societies for Experimental Biology 2014;28:407787.

[29] Calzado-Martin A, Mendez-Vilas A, Multigner M, Saldana L, Gonzalez-Carrasco JL, Gonzalez-Martin ML, Vilaboa N. On the role of RhoA/ROCK signaling in contact guidance of bone-forming cells on anisotropic Ti6A14V surfaces. Acta biomaterialia 2011;7:1890-901 .

[30] Symons M. Rho family GTPases: the cytoskeleton and beyond. Trends in biochemical sciences 1996;21:178-81.

[31] Gao L, Gorski JL, Chen CS. The Cdc42 guanine nucleotide exchange factor FGD1 regulates osteogenesis in human mesenchymal stem cells. The American journal of pathology 2011;178:969-74.

[32] Zhang C, Dai H, de Crombrugghe B. Characterization of Dkk1 gene regulation by the osteoblast-specific transcription factor Osx. Biochemical and biophysical research communications 2012;420:782-6.

[33] Chen D, Li Y, Zhou Z, Xing Y, Zhong Y, Zou X, Tian W, Zhang C. Synergistic inhibition of Wnt pathway by HIF-1alpha and osteoblast-specific transcription factor osterix (Osx) in osteoblasts. PloS one 2012;7:e52948.

[34] Wang X, Goh CH, Li B. p38 mitogen-activated protein kinase regulates osteoblast differentiation through osterix. Endocrinology 2007;148:1629-37.

[35] Nakashima K, Zhou X, Kunkel G, Zhang Z, Deng JM, Behringer RR, de Crombrugghe B. The novel zinc finger-containing transcription factor osterix is required for osteoblast differentiation and bone formation. Cell 2002;108:17-29.

[36] Schlessinger K, Hall A, Tolwinski N. Wnt signaling pathways meet Rho GTPases. Genes \& development 2009;23:265-77.

[37] Lechel A, Rudolph KL. Rho GTPase and Wnt signaling pathways in hepatocarcinogenesis. Gastroenterology 2008;134:875-8.

[38] Van Aelst L, D'Souza-Schorey C. Rho GTPases and signaling networks. Genes \& development 1997;11:2295-322.

[39] Karnoub AE, Symons M, Campbell SL, Der CJ. Molecular basis for Rho GTPase signaling specificity. Breast cancer research and treatment 2004;84:61-71. 
[40] Rawadi G, Vayssiere B, Dunn F, Baron R, Roman-Roman S. BMP-2 controls alkaline phosphatase expression and osteoblast mineralization by a Wnt autocrine loop. Journal of bone and mineral research : the official journal of the American Society for Bone and Mineral Research 2003;18:1842-53.

[41] Rossol-Allison J, Stemmle LN, Swenson-Fields KI, Kelly P, Fields PE, McCall SJ, Casey PJ, Field TA. Rho GTPase activity modulates Wnt3a/beta-catenin signaling. Cellular signalling 2009;21:1559-68.

[42] Westendorf JJ, Kahler RA, Schroeder TM. Wnt signaling in osteoblasts and bone diseases. Gene 2004;341:19-39.

[43] Wu X, Quondamatteo F, Lefever T, Czuchra A, Meyer H, Chrostek A, Paus R, Langbein L, Brakebusch C. Cdc42 controls progenitor cell differentiation and beta-catenin turnover in skin. Genes \& development 2006;20:571-85.

[44] Wan Q, Cho E, Yokota H, Na S. Rac1 and Cdc42 GTPases regulate shear stress-driven beta-catenin signaling in osteoblasts. Biochemical and biophysical research communications 2013;433:502-7. 


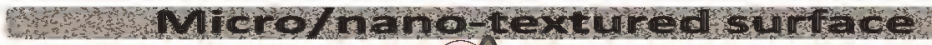

\section{Integrims un}

Plasivia Thervistaves

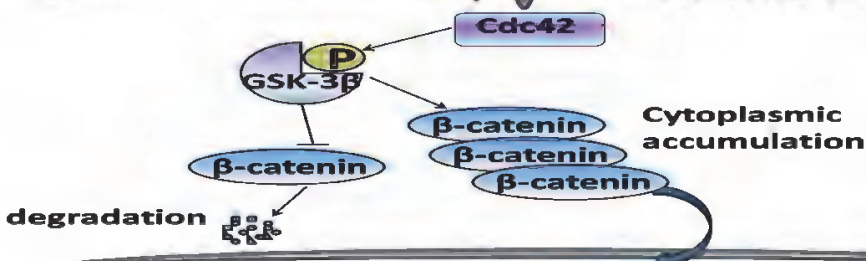

Target genes TGF/DEF B-catenin DNA MMNMMMMMYYT 
Fig.1
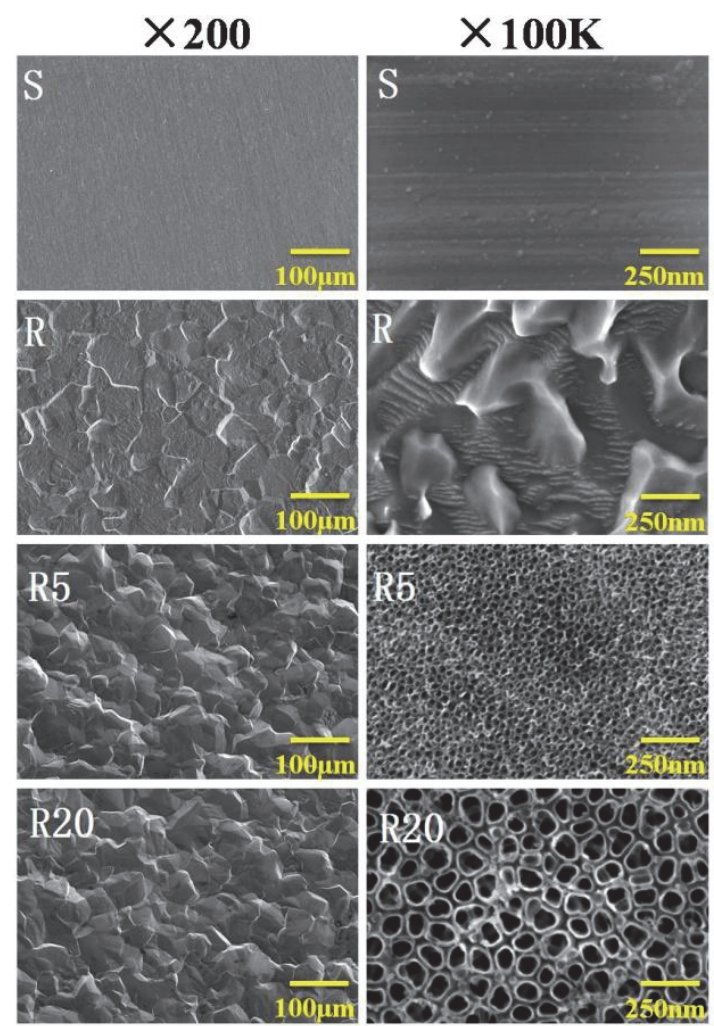

Fig.2

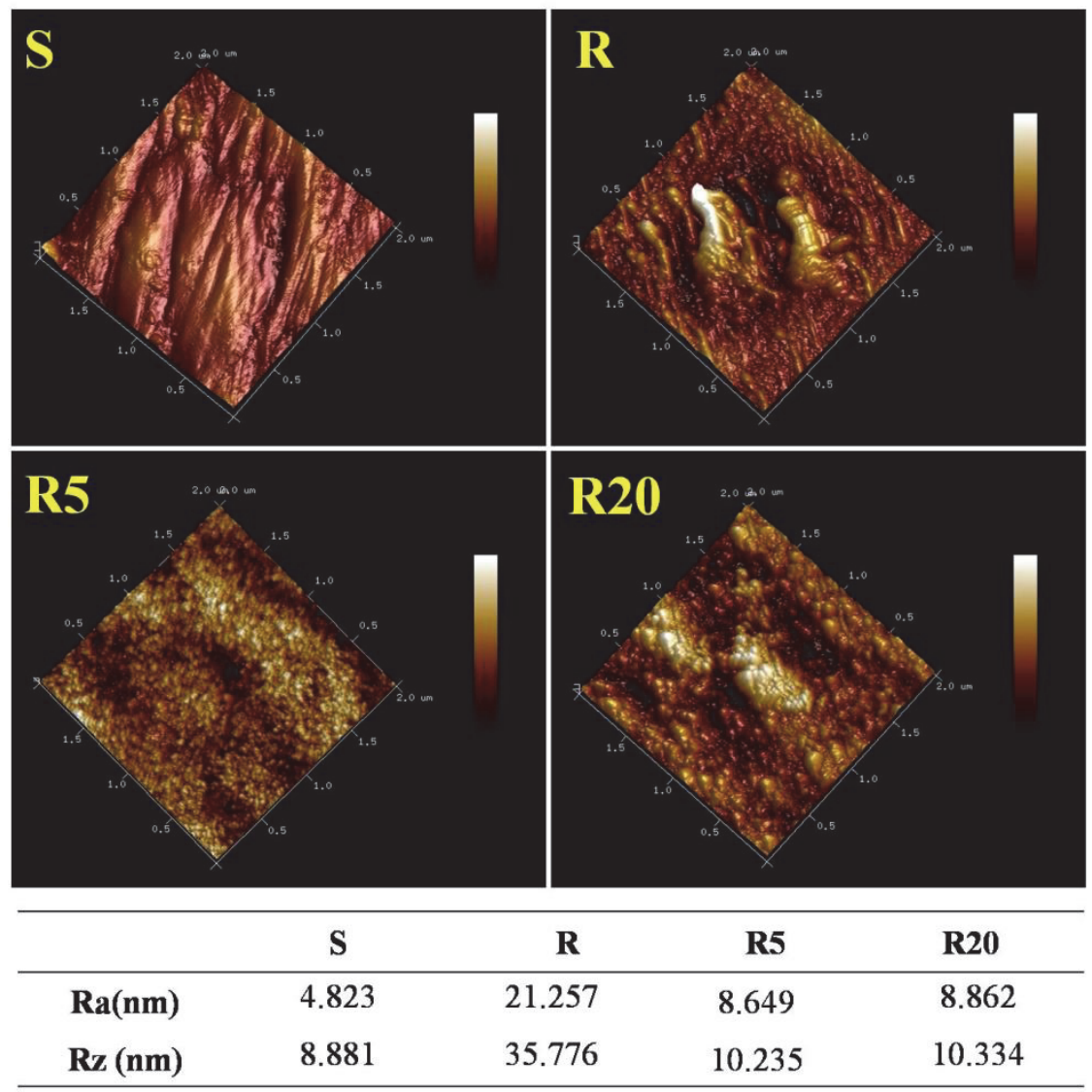


Fig.3

A
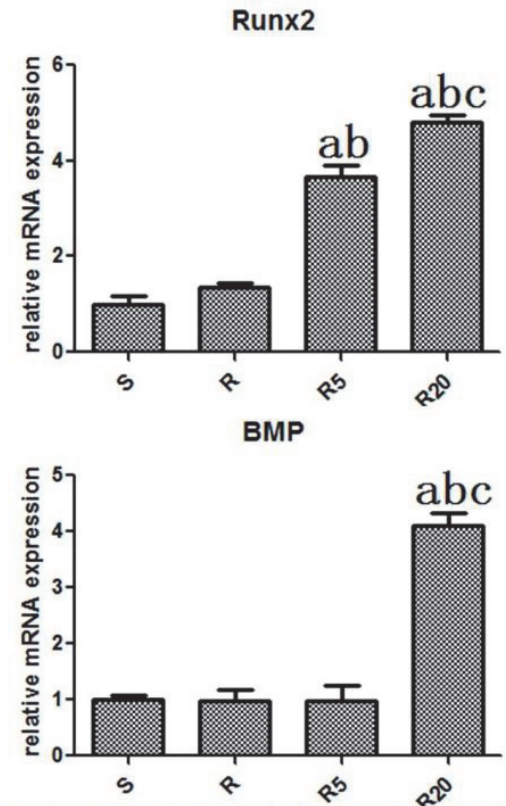

B
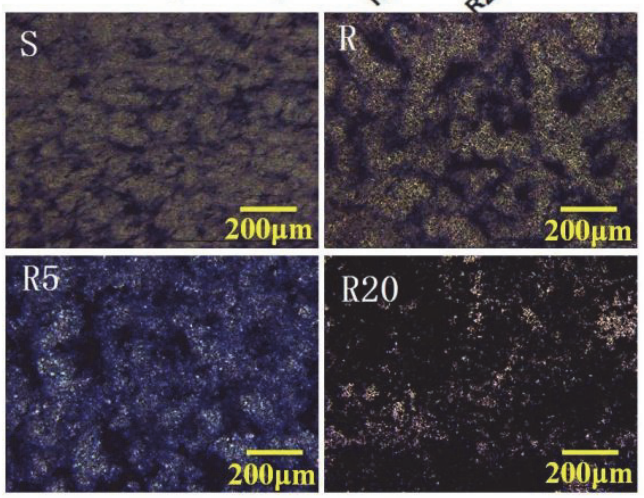

D

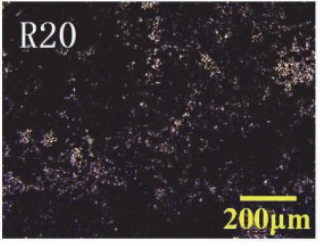

E
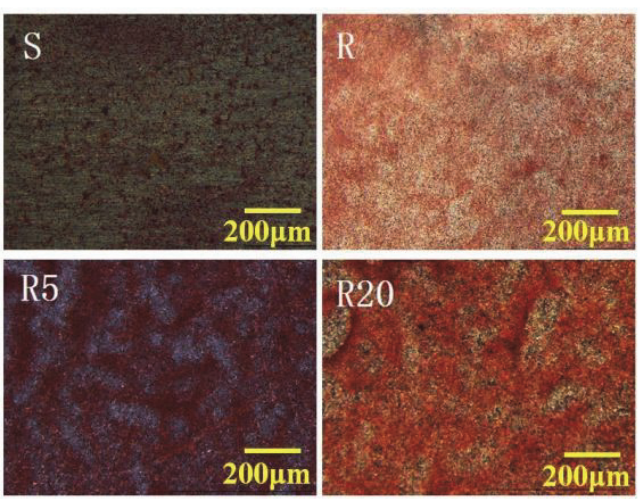

osx
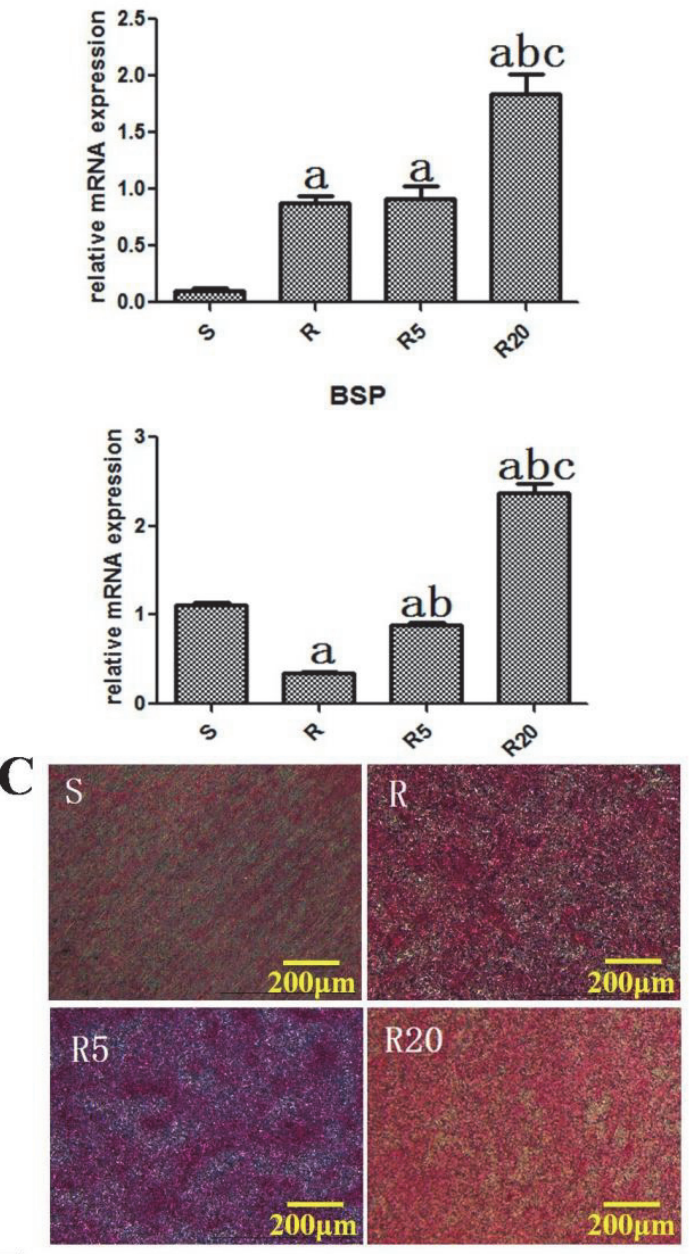

ALP vitality
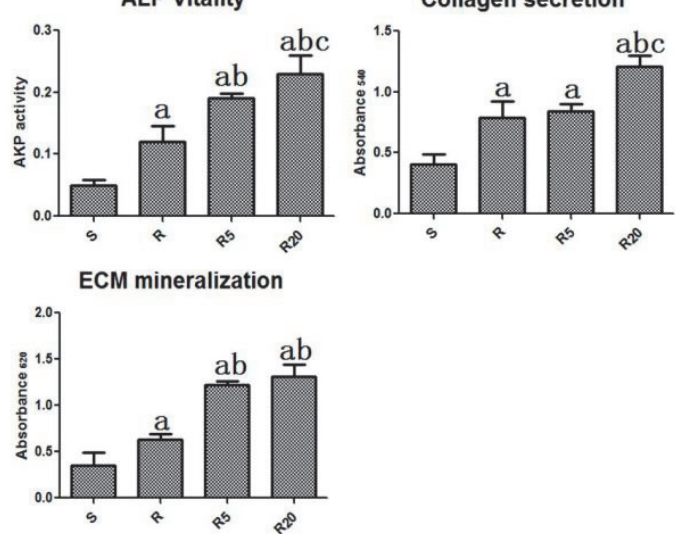
Fig.4

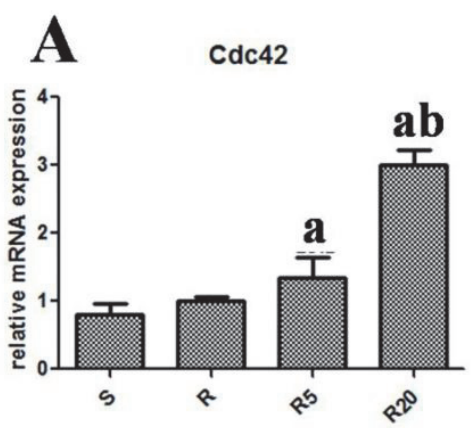

B

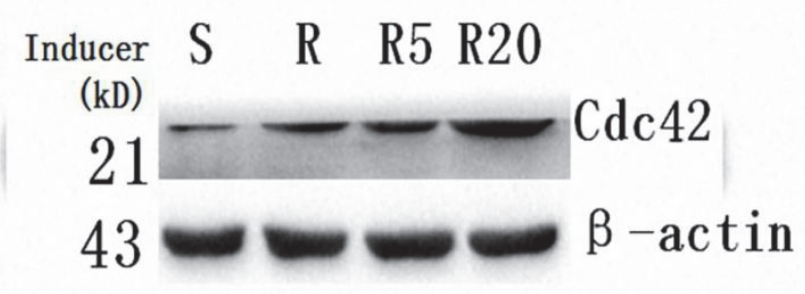

Fig.5

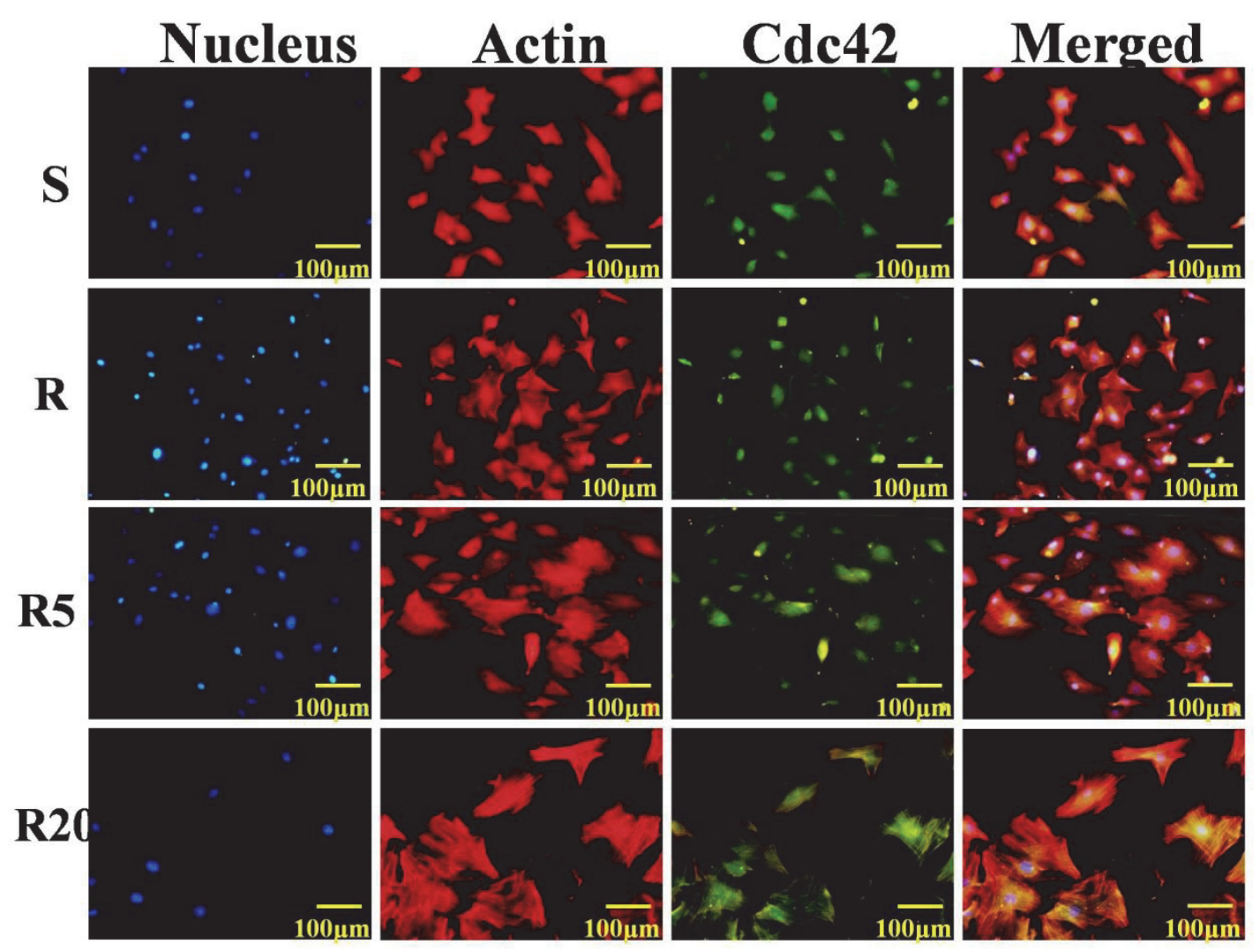


Fig.6

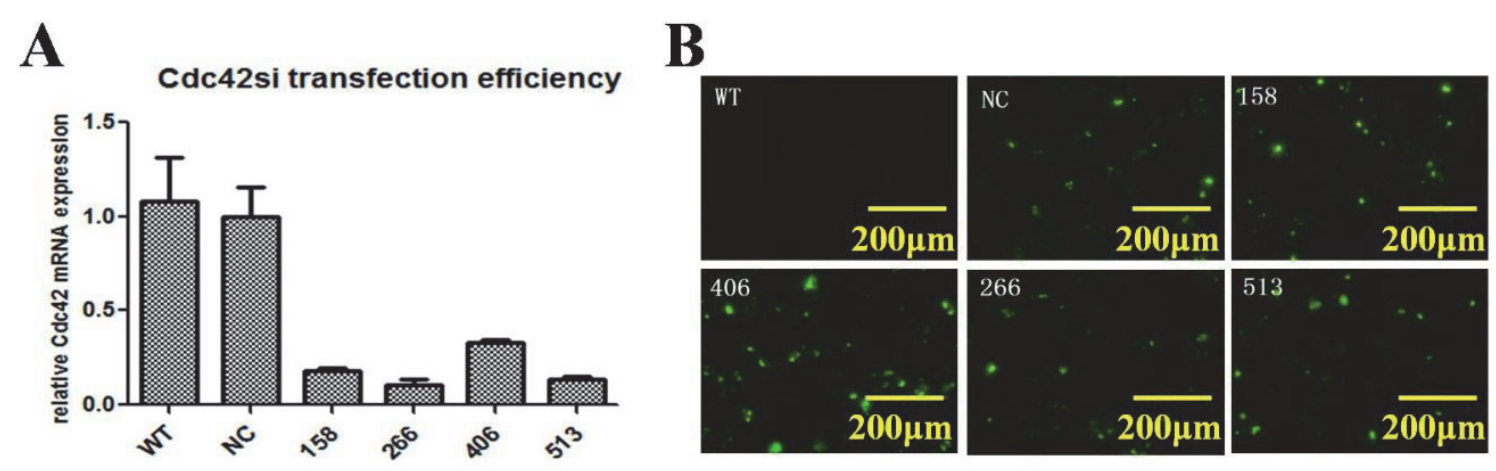


Fig. 7

A
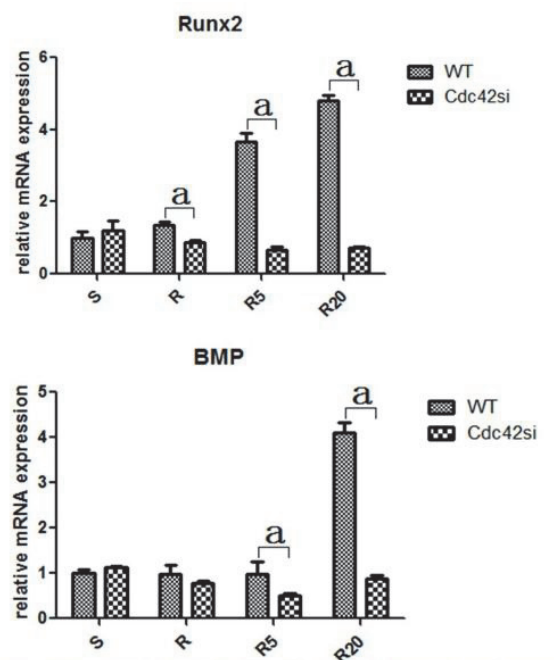

B

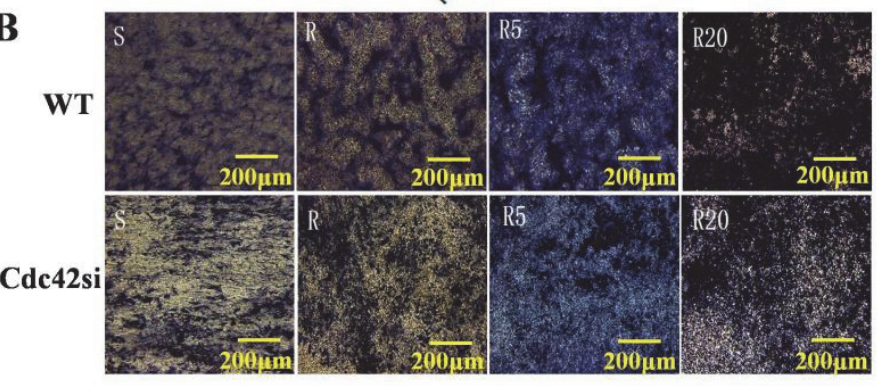

C

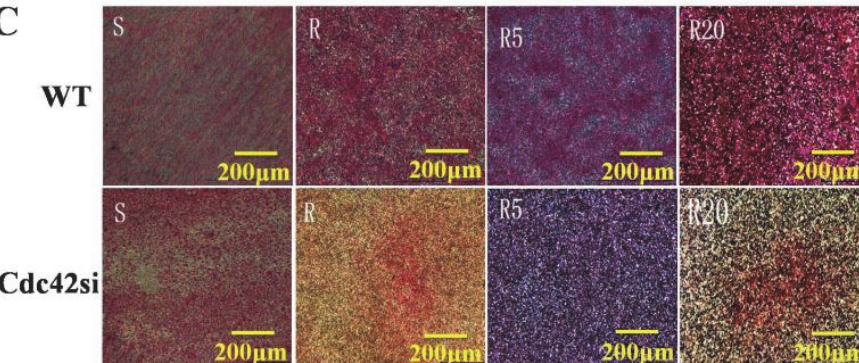

D

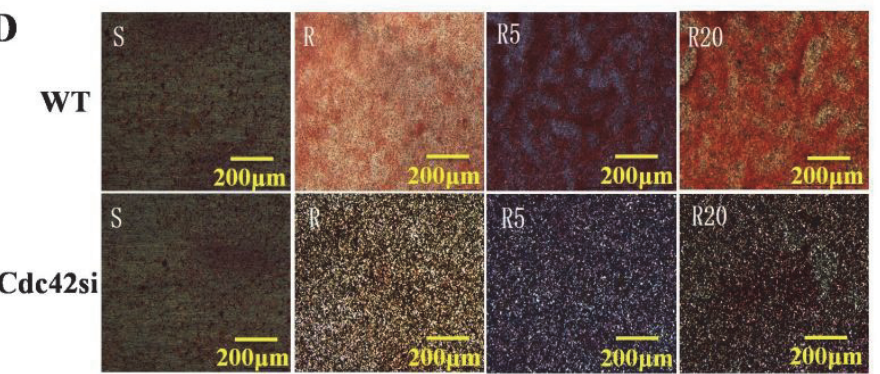

os $x$
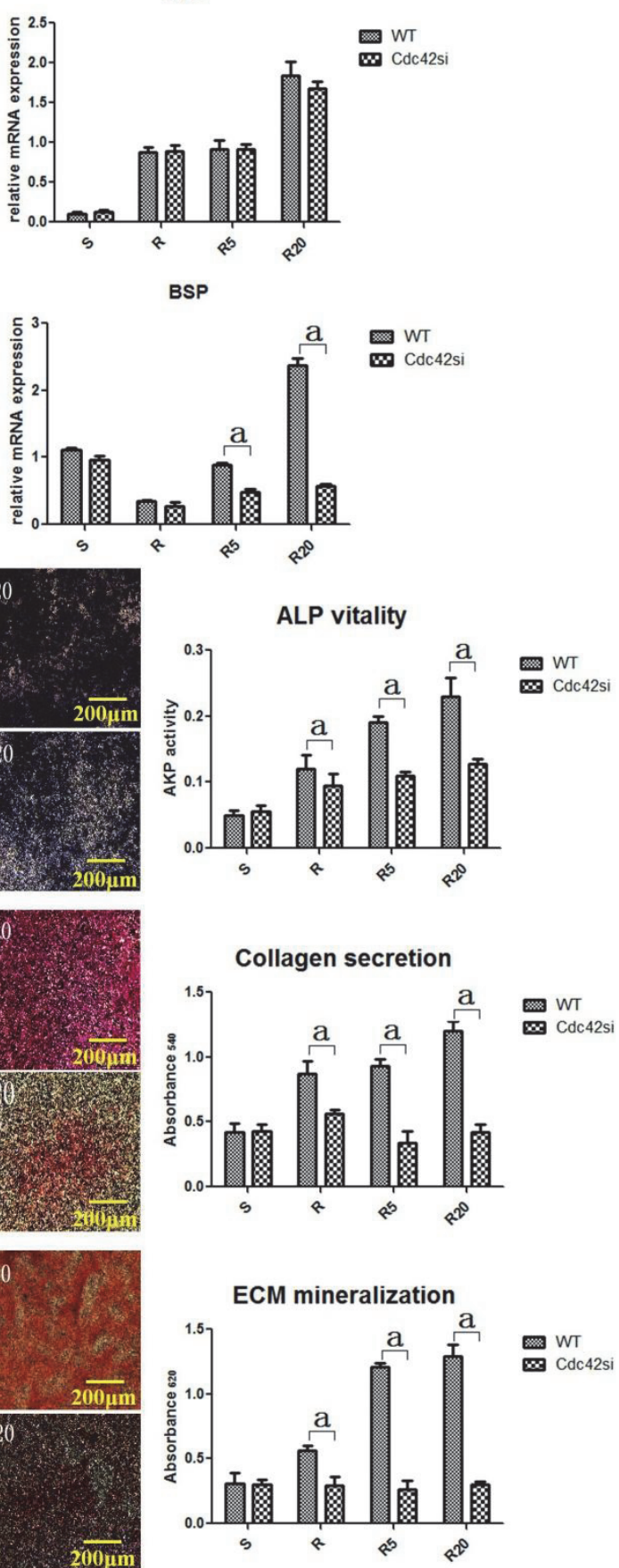
Fig.8

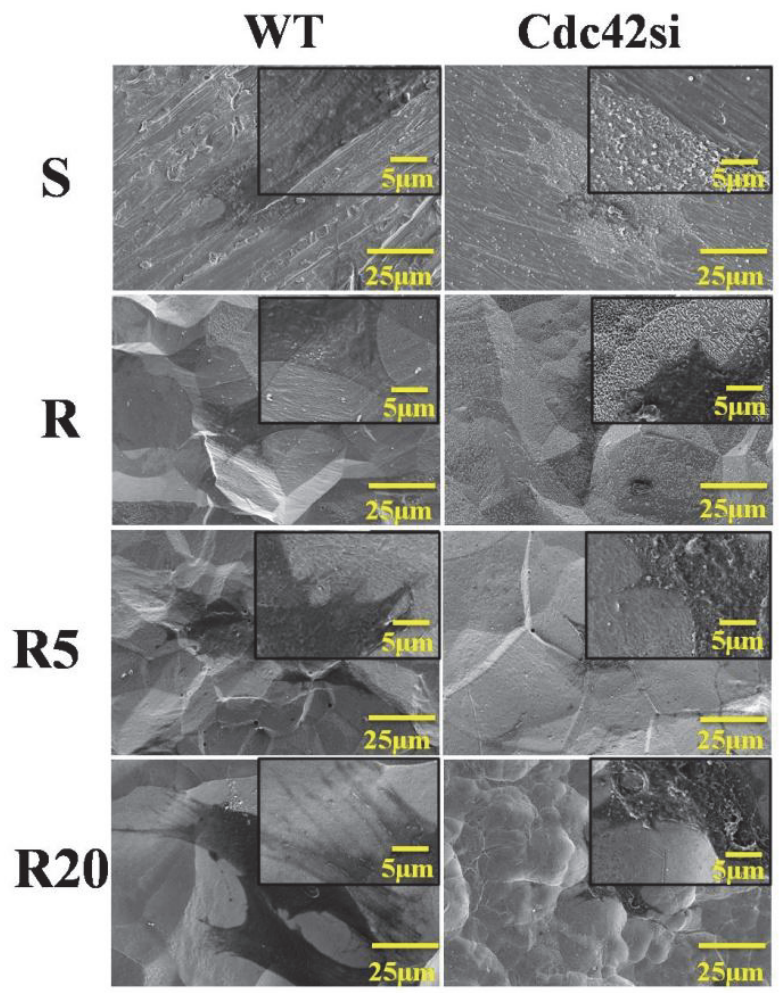

Fig.9

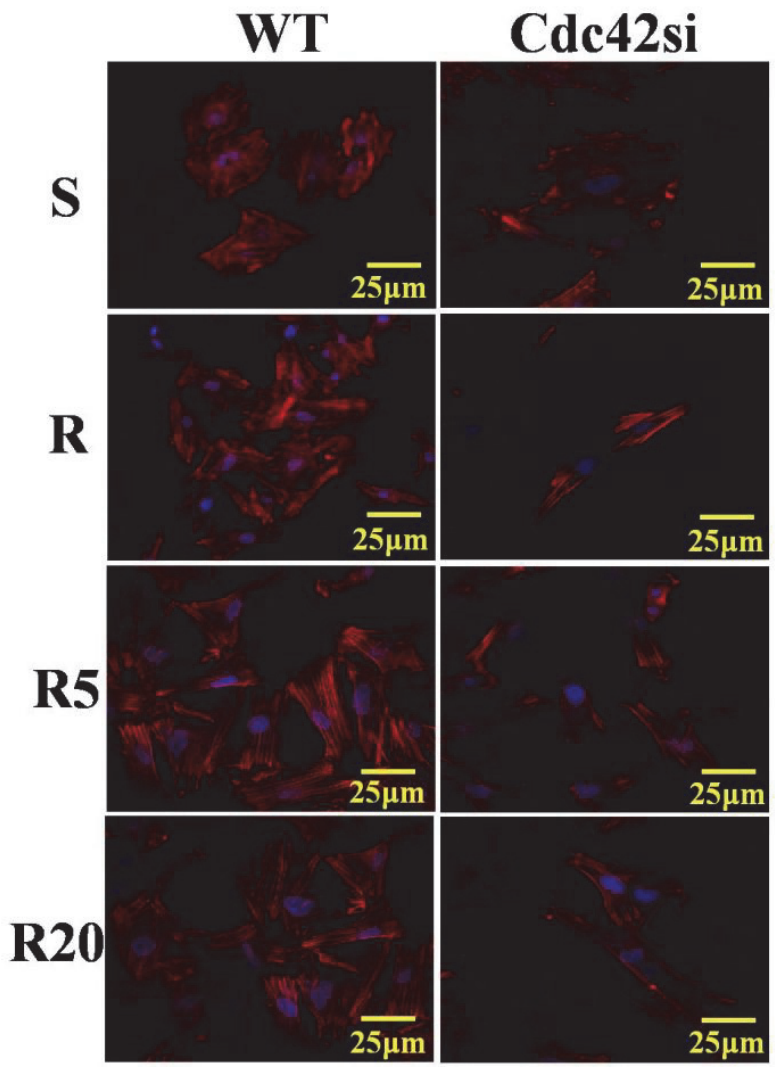


Fig.10
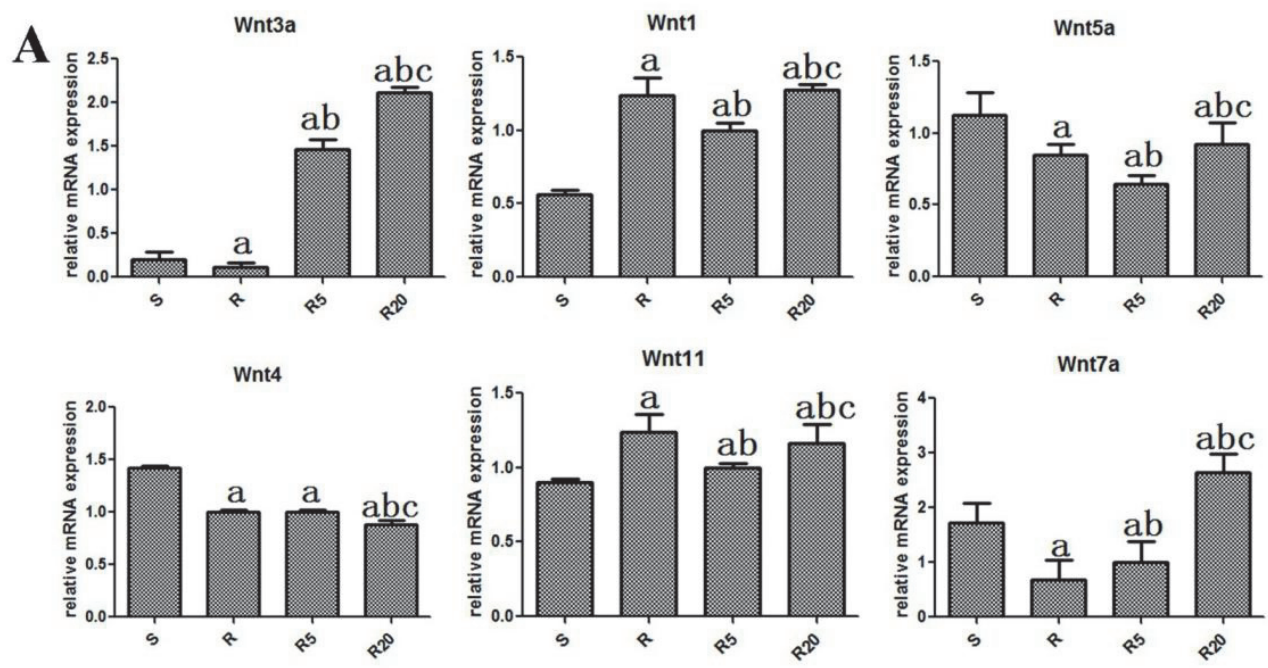

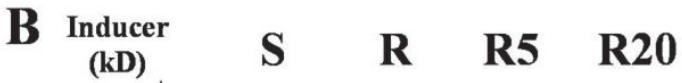
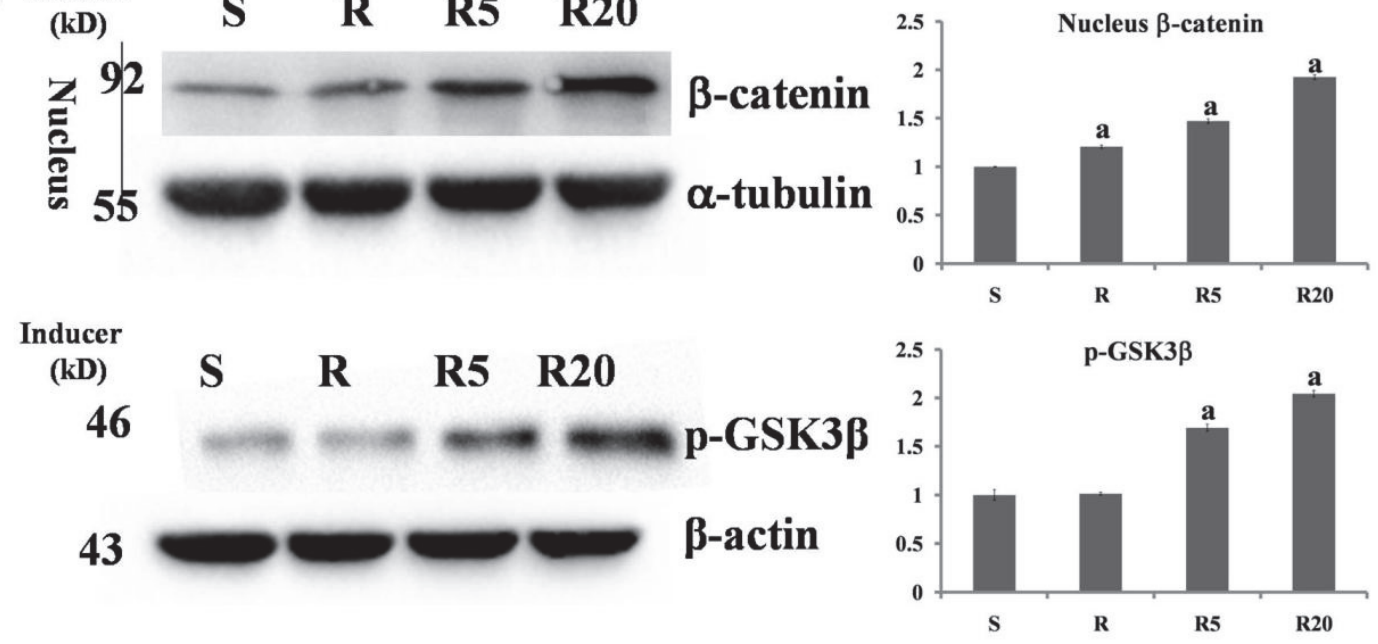
Fig.11
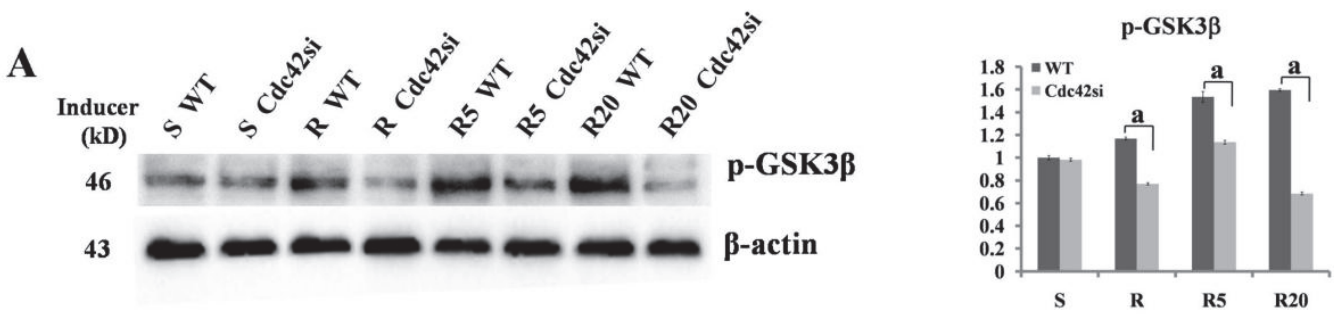

B

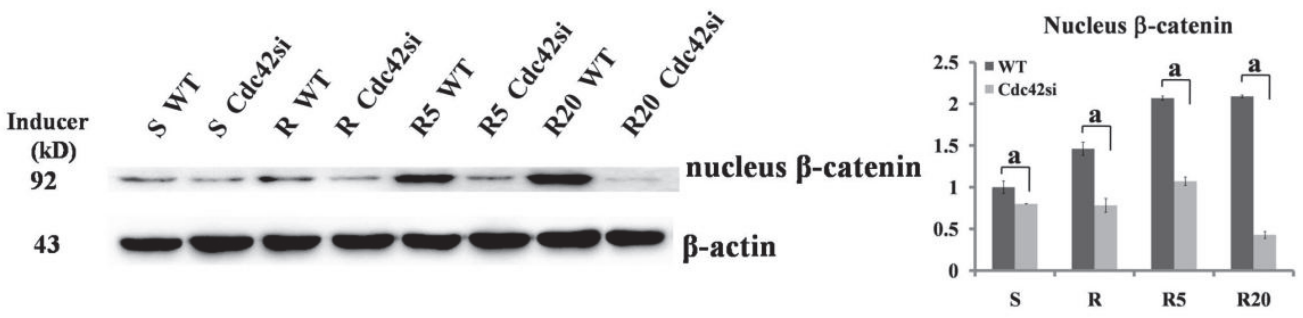

